This article has been published in:

Narrative Matters in Medical Contexts across Disciplines. Franziska Gygax and Miriam A. Locher (eds.) [Studies in Narrative 20]. Amsterdam: John Benjamins, 2015, 1-14.

https://doi.org/10.1075/sin.20.01gyg

If you want to quote from this document, please consult the page numbers in the right hand margins.

\title{
Introduction to narrative matters in medical contexts across disciplines
}

\author{
Franziska Gygax and Miriam A. Locher
}

This chapter introduces the collection on Narrative Matters across Disciplines in Medical Contexts and positions the interdisciplinary research subject. The chapter discusses the importance of narrative practices and supports the claim that 'narrative' should be given a central position within the medical humanities. The introduction explains the rationale for the chapters by the contributors to the collection and shows how they approach narratives in different medical contexts from different research traditions: literary and cultural studies, linguistics, psychology and medical training.

\section{Narrative across disciplines}

This collection of original chapters gives centre stage to the concept of 'narrative' in medical contexts. The contributors come from the disciplines of literary and cultural studies, linguistics, psychology and medicine and work with texts as diverse as autobiographies, graphic novels, Renaissance medical treatises and reports, short stories, reflective writing, creative writing, and online narratives. This results in an interdisciplinary dialogue, which demonstrates the importance of narrative in medical contexts.

Medicine itself is a field in which narrative has always been crucial since a patient going to see a doctor usually presents his or her medical problem in a narrative and the doctor listens to and interprets the "story," which is then appropriated by the medical practitioners and turned into case reports (e.g. Hunter, 1991; Hurwitz, 2006, 2010). In recent years in the field of the medical humanities narrative has become acknowledged as an issue that must be explored and theorized in depth. Literary scholars and/or professors of medicine such as Rita Charon, Brian Hurwitz, Trisha Greenhalgh, Anne Hudson ]ones, or 
Femi Oyebode, among others, have started to teach medical students how to read narratives and have

institutionalized a curriculum in narrative medicine, which not only includes courses on literary topics in connection with illness but also on philosophical themes, on the arts, and even courses on writing about their own experience for medical students (cf. Charon, 2006, 2014; Hurwitz, Greenhalgh \& Skultans, 2004; Oyebode, 2009).

The growing interest in and awareness of the function and role of narratives in our lives has affected almost all academic disciplines and scientific research communities. The 'narrative turn' has proven to be eminently important in linguistics, cultural studies, art, philosophy and literary studies and has also shaped thinking in connection with the linguistic, the cultural, spatial, visual/iconic and affective turn. However, these fields do not only explore the role and function of narrative, the concept has a long-standing and crucial position in history, anthropology, the social sciences, theology as well as psychology, medicine, and neuroscience where scholars and scientists use the concept of narrative to conduct some of their studies.

Narrative is a broad term and there are different schools of narrative analysis mainly involving literary theorists, linguists, anthropologists, philosophers and psychologists. In spite of the many different definitions (see, e.g. Lucius-Hoene \& Deppermann, 2002; Martinez \& Scheffel, 2002; De Fina \& Georgakopoulou, 2012), there is a general agreement, namely that a narrative must "involve the recounting of an event or events, [...]. And second that these events can be either real or fictitious" (Hawthorn, 2000, p. 225). Literary studies have traditionally explored issues of narrative, in particular related to prose texts. Narrative is often used together with discourse which emphasizes the discursive presentation of events (Chatman, 1978; Bal, 1997; Bamberg, 2013). Thus, any narrative text imposes an order on events and is a representation that is never identical with the event it recounts in the case of retellings of an experience. Equally, this representation does not have to have a factual, experienced counterpart (in the case of fictional or hypothetical texts). Furthermore, numerous studies in literature, linguistics, psychology and anthropology have emphasized that narrative is one of the key constituents of human identity, selfrepresentation and cultural transmission, being embedded in societal ideologies and larger discourses (e.g. Labov \& Fanshel, 1977; Davies \& Harré, 1990; Bamberg, 1997 Mattingly \& Garro, 2000; De Fina, 2003; Klapproth, 2004; Boothe, 2010; Georgakopoulou, 2007; Bamberg, 2013).

Linguistics, in particular the more recent branch of sociolinguistics and especially discourse analysis, has raised questions about the role of narrative in communication (cf. e.g. Labov, 1972, 1997; Johnstone, 1990; De Fina, 2003; Klapproth, 2004; Georgakopoulou, 2007, 2013; Georgakopoulou \& De Fina, 2012). Scholars have stressed that story telling constitutes a fundamental 'discourse unit,' which is culturally dependent and acquired in socialization processes (Klapproth, 2004, p. 144). In this context, Klapproth (2004, p. 103) 
speaks of two fundamental functions that narratives serve: (1) a cognitive need: 3 "narratives are a means of structuring and processing personal human experience"; and (2) a social need: "narratives are a means of communicating such experience to others and thus sharing it" (italics in original). With respect to the latter, oral storytelling is also considered an interactive event and many studies have demonstrated how narrators and listeners co-construct narratives (e.g. Schegloff, 1997).

While much of the early studies in linguistics focused on the structure of the personal anecdotal high-point narrative that is orally performed (see Labov \& Waletzky, 1967; Labov 1972, 1997; Labov, 2013), more recent research has taken on board the idea of how narrators position themselves and others in their story worlds and have thus made an explicit link to the study of identity construction and positioning theory, a concept derived from discursive psychology (see, e.g. Davies \& Harré, 1990; Bamberg, 1997; De Fina, 2003; Bamberg, De Fina \& Schiffrin, 2011). The field has also moved beyond the high-point narrative to include the study of (often oral) 'life stories' (e.g. Johnstone, 1990; Schiffrin, 2000; De Fina, 2003; Bamberg, 2009) and 'small stories' (e.g. Bamberg, 2007; Georgakopoulou, 2007, 2013). The latter are defined as "stories about short (fragmented, open-line) tellings about self and other of ongoing, future or shared events, allusions to tellings, deferrals of tellings, etc." (Georgakopoulou, 2013, p. 59).

Taking into account the numerous disciplines and schools with very different academic traditions, it is evident that no consensus on a singular approach to the study of narrative can be reached. Therefore, our book with contributions from the fields of linguistics, literary studies, medicine, and psychology does not aim at providing a comprehensive, theoretical approach either. Instead, the chapters serve to demonstrate how narratives in medical contexts inspire and expand theoretical research in different disciplines, and, by means of sharing a joint focus, serve to encourage scholars to read across disciplines. Besides our individual disciplinary focus on narrative we all share a deep interest and engagement in advancing the interdisciplinary field of medical humanities, which, on a more general note, also endeavours at improving doctor-patient communication. In the next sections we briefly sketch the advances in the field of 'illness narratives' before we explain what the individual contributions of this collection add to the understanding of narrative in medical contexts.

\section{Illness narratives}

In the recent past a number of interdisciplinary publications have explored the relation between narrative and illness apart from general theoretical

investigations on narrative and other cultural narratives (e.g. autobiography; cf., e.g. Brockmeier \& Carbaugh, 2001), which all emphasize the narrative issue dominant not only in the field of medicine but also in many other fields related to all kinds of medical matters. In what follows we want to briefly discuss more recent developments (roughly since 2000) in the field of illness and narrative; we will not provide an overview since the 1980s when scholars began theorizing narrative in relation to illness since there are studies that quite 
comprehensively expand on the developments of this interface, among which for example Hydén and Brockmeier's (2008) Health, Illness and Culture, Rita Charon's (2006) Narrative Medicine, or Hurwitz, Greenhalgh and Skultans' (2004) Narrative Research in Health and IIIness. These studies all refer back to the influence of literary theorists and narratologists like Mieke Bal, Mikhail Bakhtin, Seymour Chatman, Gérard Genette, or Shlomith RimmonKenan, but of course they also thematize the tradition of narrative in the medical field besides pointing out the long-lasting presence of literary texts by famous writers (suffice it to name Thomas Mann's The Magic Mountain) that give an account of an illness. It is this latter interface between literature and illness that we will first address in our overview because on the one hand one of us editors is a literary scholar, and on the other hand the fairly new fields literature and medicine ${ }^{1}$ and narrative medicine ${ }^{2}$ have become influential in promoting and advancing medical humanities, ${ }^{3}$ the larger field to which all our contributions belong.

From 2009 to 2013 the editors were involved in a research project entitled 'Life (beyond) Writing': Illness Narratives, funded by the Swiss National Science Foundation (see Gygax, this volume; Locher, Koenig \& Meier, this volume). Using the term illness narratives for our interdisciplinary research project (literary studies, linguistics and medicine), underlines our own training as scholars and teachers in literary and cultural studies and linguistics. Yet in clinical contexts illness narrative is also used to denote the story a patient tells his/her doctor. Arthur Kleinman, a key figure in medical anthropology, already uses the term in his canonical work The Illness Narratives: Suffering, Healing and the Human Condition (1988) and defines it as follows:

The illness narrative is a story the patient tells, and significant others retell, to give coherence to the distinctive events and long-term course of suffering. (Kleinman, 1988, p. 49)

Although Kleinman refers to the patients in doctor-patient encounters, his definition can be applied to a whole range of patients, including well-known authors who write on their experience as patients. Besides these so-called autopathographies ${ }^{4}$ there are other narrative forms dealing with the experience of illness. In our interdisciplinary research project we have also explored the role and function of narrative in the reflective writing texts by medical students (e.g. Gygax, Locher \& Koenig, 2012; Locher \& Koenig, 2014). We very loosely apply the term illness narrative to these texts as well as they comment on an encounter with a patient during the students' internships. This broad use of illness narrative enables us to approach a whole range of very different texts that all deal with the representation of illness and are characterized by their narrative impact.

\footnotetext{
${ }^{1}$ See Hawkins and McEntire Chandler's (2000, pp. 3-4) explanations of the field in their introduction to Teaching Literature and Medicine.

2 See the definition provided by the program of narrative medicine at Columbia University: $<$ http://ce.columbia.edu/narrative-medicine>

${ }^{3}$ See the definition provided at <http://medhum.med.nyu.edu/>

${ }^{4}$ The term was first used by Hawkins (1993) in Reconstructing IIIness.
} 
In literary studies, scholars already began theorizing illness narratives in the $1970 s^{5}$ and since then the number of influential scholars working in the fields of literature and medicine, auto/biography and auto/pathography has been increasing (e.g. Couser, 1997; Hunter, 1991; Hawkins, 1993; Epstein, 1995; Jones, 2013; Squier, 1994). As the sub-fields imply, different theoretical concepts and positions are used in the discussions of illness narratives, and, depending on their theoretical orientation, scholars focus more on issues of self-representation (autobiography studies) or on the social and cultural constructions of illness (literature and medicine/cultural studies). There are no clear-cut differentiations in the discussions since scholars often engage with concepts like agency/empowerment, subjectivity/identity, and embodiment/body with a specific focus. In particular, the theorization of the body has seen a wide range of developments since Judith Butler's (1993) seminal work Bodies That Matter. Furthermore, in the very recent past the "new" medium of the graphic memoir, also termed autographics (Whitlock, 2006), on the experience of illness has seen a striking rise of academic attention (e.g. Chute \& DeKoven, 2006; Squier, 2008).

In her illuminating study Treatments: Language, Politics and the Culture of IIIness, Lisa Diedrich (2007) demonstrates that in illness narratives complex cultural contexts are at work and influence the way the experience of illness is represented. Her approach vividly illustrates a scholar's work that considers crucial issues like gender, race, and class, besides thematizing what it means for a reader to be confronted with suffering and loss (of life). Einat Avrahami (2007) in her work Invading Body: Reading Illness Autobiographies focuses on the relations between the sick self and its embodiments by challenging some of the cultural constructionists' positions and argues for an approach that takes the concrete, material situation of the suffering body into a much more direct consideration. She, too, like Diedrich, though with a different theoretical framework, addresses issues of the ethical response on the side of the reader. These two more recent studies on illness narratives not only illustrate the enormous ethical response such narratives claim, they also mirror the influence of affect studies, ${ }^{6}$ a fairly new field in cultural studies.

Leigh Gilmore, the influential theorist in autobiography studies, has elaborated on the impact an account of illness has with regard to "mastery" of one's chronic pain in "Agency Without Mastery: Chronic Pain and Life Writing" (Gilmore, 2012) and claims agency without mastery for such autobiographers because, as she puts it, "the human and pain" are always linked, and so are "dependence and interdependence" (Gilmore, 2012, p. 95). Ann Jurecic's (2012) Illness as Narrative contributes to the on-going debate in how far illness narratives are aesthetically challenging and to what extent they demand narrative empathy. Jurecic refers to Eve Sedgwick's (2003) reparative reading ${ }^{7}$ and quite

\footnotetext{
${ }^{5}$ E.g. Joanne Trautmann Banks, who, as a professor of literature, began working at the Pennsylvania State University Medical School in 1972.

${ }^{6}$ See The Affect Theory Reader (Gregg \& Seigworth, 2010).

7 Sedgwick (2003) proposes this "reparative reading" as a response, but not as a contradiction, to the "paranoid reading" that governed much of the last four decades of criticism in cultural theory. Reparative reading means engaging in a reading that addresses affects such as for example shame (Sedgwick, 2003).
} 
convincingly argues for a reader's critical and compassionate response (see also Diedrich in this book) at the same time. She critically comments on the existing fractions between the more theoretical orientation of cultural critics and the medical humanists with more pragmatic and didactic objectives. Jurecic's study is a successful attempt at critically and theoretically engaging with illness narratives on suffering and elaborating on the implications of cultural practices.

As these studies demonstrate, there is a tendency in literary/cultural studies to discuss illness narratives with an increasing tendency to consider and theorize the reader's position and response. In our view, this concern can be extended to the crucial communicative situation of the patient-doctor relationship, and the discursive negotiation of health communication. In this sense, linguistics also has a long tradition of studying health discourse (see Davis, 2010). The 2014 Routledge Handbook of Language and Health Communication (edited by Hamilton \&

Chou) aptly exemplifies the scope of the field. The study of narrative in health contexts from a linguistic perspective played a crucial role early on (e.g. Labov \& Fanshel, 1977, work with narrative anecdotes in psychotherapy) and is still a vital aspect today. For example, next to the study of oral narratives in health related contexts such as doctorpatient interaction, counseling and therapy, the new electronic communication technologies provide platforms for the exchange of professional-lay and peer-to-peer health information, which contain instances of narratives (e.g. Hamilton, 1998; Locher, 2006; Harrison \& Barlow, 2009; Kouper, 2010; Smithson et al., 2011; Gordon, this volume). The latter sources quoted all deal with contexts in which medical issues are negotiated, ranging from health support mailing lists, health advice columns, to health discussion boards in online fora, which contain narratives that may function as sharing experience and advice. In the more interdisciplinary field, Rita Charon (2006) elucidates in her Narrative Medicine: Honoring the Stories of IIIness how reading and studying (literary) illness narratives from all kinds of contexts can contribute to bridge the divide between (bio)medical care and ethical response and ultimately improves medical care (see also Oyebode \& Tischler, this volume). The chapters in our collection wish to add to this dialogue.

\section{Structure of the collection}

The chapters in this collection are organized into three parts. Part I consists of three chapters that contain discussions of narrative texts on illness and medicine that are approached with a literary and cultural studies angle. Part II gives centre stage to narrative practices in health contexts, which are discussed from the angle of psychology and linguistics. Part III consists of two chapters that explicitly deal with the medical humanities and the role of narratives within this field. 
Annette Kern-Stähler and Anna Thiemann's chapter is entitled Autism and the American Dream: Progress and recovery in the American autie-biography (Chapter 2). The literary scholars focus on representations of autism in selected American autobiographies, so-called autie-biographies claiming that the American dream is inscribed in these narratives, although in different ways. Values like perseverance and success have begun to replace notions of disability and "defect" appearing in earlier autie-biographies. KernStähler and Thiemann's discussion of three more recent narratives illustrate that concepts like gender, class, and race need to be considered since they have an enormous impact on the respective social

and cultural context in which these narratives are embedded. The three narratives under discussion reveal a specific interface of disability and the American dream because their autobiographers integrate the experience of autism into their respective lives depending on their identities as for example an Asian American or a working-class lesbian. Moreover, the specific symptoms of autism also influence the different narrative structures of these texts, yet all three examples tend to prefer an episodic narrative strategy.

While Kern-Stähler and Thiemann work with texts by authors who have a condition in common, Franziska Gygax works with texts by authors who are terminally ill and reflect on their dying. In her contribution "Woundable, around the bounds": Life (beyond) writing and terminal illness (Chapter 3), Gygax argues that these autobiographers write about a realm that is unknown to us all and therefore seems to be unrepresentable in narrative, and yet, in all four texts, representations of dying and death are omnipresent, although in different ways. Gygax's references to theorists like de Certeau, Derrida, Benjamin, Sedgwick, and Lanser illustrate how language, writing and reading are related to death because language is the means to express absence/loss. In spite of this theoretical focus on the interface between death and narrative Gygax's analysis provides evidence that these so-called authothanatographies tend to become actual life writing texts as they demonstrate the belief in writing and narration about their authors' (past) lives. The study of the reader's affective response to such narratives is a further objective in this chapter because, as Gygax claims, knowing that their writers are confronted with severe bodily suffering and will die, a reader tends to become emotionally involved, which shapes the reader's ethical attitude towards illness and dying as a whole.

The last chapter dealing with narrative texts on illness is by Dominique Brancher, a scholar of French literature and culture, who takes us to Pox pain and redeeming narratives in Renaissance Europe (Chapter 4). The studied sources deal with the different types of accounts of the pox, an illness that was new to the Europeans of the sixteenth century, that emerged in Italy, France and Germany. First person narrative accounts that do not only describe the illness from a pathological perspective but that are renditions from the sufferer's perspective demonstrate the great potential that the narrative form offers the patients to make sense of their suffering and to cope with their dying. Brancher 
shows how these new autopathological texts announce the genre of observationes and curationes, which established themselves later in the second half of the sixteenth century.

\section{Part II: Narrative practices in health contexts}

While Part I deals with written texts in the form of novels or reports, the data studied in Part II focuses on practices in health contexts that contain narratives as an important element. In Chapter 5, Brigitte Boothe discusses IIIness narratives in

the psychotherapeutic session. She works with a large corpus of psychotherapeutic sessions recorded in Switzerland and Germany that were conducted in German and then transcribed. From her long-standing experience as a psychoanalyst and a trained literary scholar, Boothe identifies prototypical patterns of narrative self-thematization in the context of illness, suffering, and deficiency: the articulation of an illness career, the formulation of typical situations, the communication of disintegrative processes, and the narrative evocation of emotionally stirring events. Boothe shows how central narrative analysis is for psychotherapy and argues that this method can be used to show how "dramaturgical organizations of oral narratives in the psychotherapeutic context are related to interpersonal dynamics and the curative potential of the patient-therapist relationship" (p. 73).

The focus on patient narratives is also retained in Chapter 6 by Gabriele Lucius-Hoene, Sandra Adami and Janka Koschack, whose work is entitled Narratives that matter. Illness stories in the 'third space' of qualitative interviewing. The authors work with German data collected and prepared for a website project entitled DIPEx (Database of Individual Patients' Experiences; www.krankheitserfahrungen.de). Extracts from the transcribed interviews and video clips are placed online with the aim of giving space to the patient's voice and to thus provide other patients who suffer from similar conditions a platform to find personal information on their experience. The authors reflect on the particular method of interviewing employed in the project and focus on the dynamics that develop between the patient who tells his or her illness narrative and the interviewer during the narrative. They argue that a transient 'third space' is created in the course of the interview, which allows the patients to explore new subject positions in their narrative. This possibility is largely facilitated by the conscious attempt of the interviewer to deconstruct hierarchical imbalance and to empower the patient by establishing an expert identity for him or her.

Following two chapters that work with narratives derived from face-to-face encounters, discourse analyst Cynthia Gordon turns to a linguistic study of narratives that were written in a computer-mediated context. Her contribution is entitled "I would suggest you tell this $\wedge^{\wedge \wedge}$ to your doctor": Online narrative problem-solving regarding faceto-face doctor-patient interaction about body weight (Chapter 7). She works with data from a peer-to-peer platform that deals with weight loss and examines one thread in which a problematic doctor-patient encounter is recounted and discussed. By drawing on the concept of 'small story' (Georgakopoulou, 2007), Gordon demonstrates how the 
interactants engage in a metadiscourse on doctor-patient interaction and co-construct the narrative through several intertextual linking strategies. Her analysis supports Sarangi's (in press) finding that interactants evoke a 'role responsibility framework,' i.e. the "participants attribute responsibility for the problematic encounter to both the doctor and patient/original poster" (Gordon, p. 117).

Chapter 8 is the last in Part II and turns to reflective writing texts that medical students wrote in connection with a clinical communication skills course. Locher, Koenig and Meier approach the students' texts, which focus on an encounter with a memorable patient, from the perspective of corpus linguistics and linguistic genre studies and ask what role 'narrative' plays within the texts. They report that there is indeed a narrative core in the sense that the students had to choose to recount a personal experience of a memorable encounter. Nevertheless, the texts also contain elements of the medical case report, drama (by means of constructed dialogue) and essay writing. The texts demonstrate that reflective writing is a valuable tool for the students to become aware of their clinical communication skills and the narrative core that underlies many doctor-patient encounters. For the instructors, the texts raise important issues about topic choice and role conflicts that can be discussed in the classroom.

\section{Part III: Narratives and the medical humanities}

The final part of the collection gives the word to scholars who work as educators within the medical humanities or critically challenge some of the work being done in this field. Lisa Diedrich in her contribution entitled Against compassion: Attending to histories and methods in medical humanities; Or, doing critical medical studies (Chapter 9) explores the history and emergence of medical humanities in order to critically discuss the so-called "soft place" of this field. By analysing the narratives of the formation of medical humanities, Diedrich gains insight into dynamics at work when such a field becomes part of the academy. She questions the notion of compassion dominant in the medical humanities because, as she claims, compassion tends to overshadow the need for a structural analysis of medicine and medical care. Instead, Diedrich suggests we do critical medical studies and integrate theory from different disciplines, thus being able to deal with new theories and politics in medicine. Discussing David B.'s Epileptic, Diedrich illustrates what she means by doing critical medical studies, namely paying clinical and critical attention to the numerous spaces that such an illness narrative opens up.

Femi Oyebode and Victoria Tischler both have longstanding experience as educators of medical humanities courses at medical schools. In their chapter Applying narrative to medical education: Medicine and storytelling (Chapter 10), they first reflect on the importance of introducing narratives to students of medicine by discussing extracts from Anton Chekov's work, who himself was a doctor and writer. They show how Chekov's insights can be used to show medical students that his writing is of interest to a modern audience with respect to the conditions he describes, as well as with respect to how narrative can function as a means to explain the deeply human condition of experiencing 
illness. In the second part of their chapter, they discuss the experience of present-day medical

students engaging in creative writing by analysing feedback given by the students on this task. The results show that the students are quite ambivalent about incorporating narrative into their practice and many orient primarily to the biomedically inspired curriculum. Some report being confused about the task state that they want more guidance, and consider narrative 'inappropriate' within their education. Others, however, also consider the task refreshing. All in all, Oyebode and Tischler report that the "students are acculturated to accept, somewhat uncritically, the dominant paradigm of biomedicine." This is something that is worth challenging as they demonstrate in their chapter.

The collection shows the richness and scope of the concept narrative and demonstrates how crucial it is for practices in medical contexts. We hope that the insights presented in this collection will prove to be enriching and promote interdisciplinary work. Apart from this fruitful exchange, a number of issues need to be particularly emphasized as they emerge as crucial in most contributions. First, empowerment is an effect that most narratives evoke, be it experienced by the suffering autobiographer, the patient, practitioner, the medical student, or the reader. Second, being involved in this interdisciplinary project, we scholars have profited from a growing awareness of the great variety and multivocality of narratives on the experience of illness besides paying heed to the many different angles from which these narratives can be perceived, read, and analysed. Striking examples concern the aesthetic and affective effects a literary and lay illness narrative can have and which are approached and explored with the respective disciplinary concepts and tools. Thus, the wide range of approaches assembled in this collection provide a comprehensive view on illness and health and on the multiple ways in which they are represented in narrative.

\section{Acknowledgements}

We would like to thank the Swiss National Science Foundation for funding the research project 'Life (beyond)': Illness Narratives (126959, 144541), which inspired this collection, and the Freie Akademische Gesellschaft (Basel) for supporting editorial work.

\section{References}

Avrahami, Einat (2007). Invading body: Reading illness autobiographies. Charlottesville/London: University of Virginia Press.

Bal, Mieke (1997). Narratology. Toronto: The University of Toronto Press.

Bamberg, Michael (1997). Positioning between structure and performance. Journal of Narrative and Life History, 7, 335-342.

Bamberg, Michael (2007). Stories: Big or small? Why do we care? In M. Bamberg (Ed.), Narrative - 
Bamberg, Michael (2009). Identity and narration. In P. Huhn, J. Pier, W. Schmid \& J. Schonert (Eds.), Handbook of narratology (pp. 132-143). Berlin: Mouton de Gruyter.

Bamberg, Michael (2013). Narrative discourse. In C. E. Chapelle (Ed.), The encyclopedia of applied linguistics (pp. n.p.). Oxford, UK: Wiley-Blackwell.

Bamberg, Michael, De Fina, Anna, \& Schiffrin, Deborah (2011). Discourse and identity construction. In S. Schwartz, K. Luyckx, \& V. Vignoles (Eds.), Handbook of identity theory and research (pp. 177-199). Berlin, Germany: Springer. DOI: 10.1007/978-1-4419-7988-9_8

Brockmeier, Jens, \& Carbaugh, Donal (Eds.) (2001). Narrative and identity: Studies in autobiography, self, and culture. Amsterdam and Philadelphia: John Benjamins. DOI: 10.1075/sin.1

Boothe, Brigitte (2010). Das Narrativ. Biographisches Erzählen im psychotherapeutischen Prozess. Stuttgart: Schattauer.

Butler, Judith (1993). Bodies that matter. On the discursive limits of "sex." London: Routledge. Charon, Rita (2006). Narrative medicine: Honoring the stories of illness. New York, NY: Oxford University Press.

Charon, Rita (2014). Why read and write in a clinic? The contributions of narrative medicine to health care. In H. Hamilton \& W. S. Chou (Eds.), The Routledge handbook of language and health communication (pp. 245-258). London: Routledge.

Chatman, Seymour (1978). Story and discourse. Narrative structure in fiction and film. Ithaca, NY: Cornell University Press.

Chute, Hillary \& DeKoven, Marianne (2006). Graphic narrative, special issue of Mfs: Modern Fiction Studies, 52(4), 767-782.

Couser, G. Thomas (1997). Recovering bodies: Illness, disability, and life writing. Madison, WI: University of Michigan Press.

Davies, Bronwyn, \& Harré, Rom (1990). Positioning: The social construction of self. Journal for the Theory of Social Behavior, 20(1), 43- 63. DOI: 10.1111/j.1468-5914.1990.tb00174.x

Davis, Boyd (2010). Interpersonal issues in health discourse. In M.A. Locher \& S. L. Graham (Eds.), Interpersonal pragmatics (pp. 381-404). Berlin: Mouton de Gruyter.

De Fina, Anna (2003). Identity in narrative. A study of immigrant discourse. Amsterdam: John Benjamins. DOI: 10.1075/sin.3

De Fina, Anna, \& Georgakopoulou, Alexandra (2012). Analyzing narrative. Discourse and sociolinguistic perspectives. Cambridge: Cambridge University Press.

Diedrich, Lisa (2007). Treatments: Language, politics and the culture of illness. Minneapolis, MN: University of Minnesota Press.

Epstein, Julia (1995). Altered conditions: Disease, medicine, and storytelling. New York, NY: Routledge.

Georgakopoulou, Alexandra (2007). Small stories, interaction and identities. Amsterdam: John Benjamins. DOI: $10.1075 / \sin .8$

Georgakopoulou, Alexandra. (2013). Small stories and identities analysis as a framework for the study of im/politeness-in-interaction. Journal of Politeness Research, 9(1), 55-74.

Gilmore, Leigh (2012). Agency without mastery: Chronic pain and life writing. Biography, 35(1), 83- 97. DOI: 10.1353/bio.2012.0011

Gregg, Melissa, \& Seigworth, Gregory J. (Eds.) (2010). The affect theory reader. Durham: Duke University Press. 
Gygax, Franziska, Koenig, Regula, \& Locher, Miriam A. (2012). Moving across disciplines and genres: Reading identity in illness narratives and reflective writing texts. In R. Ahmed \& B. Bates (Eds.), Medical communication in clinical contexts: Research and applications (pp. 1735). Dubuque, IA: Kendall/Hunt.

Hamilton, Heidi E. (1998). Reported speech and survivor identity in on-line bone marrow transplantation narratives. Journal of Sociolinguistics, 2, 53- 67. DOI: 10.1111/14679481.00030

Hamilton, Heidi E., \& Chou, Wen-ying S. (Eds.) (2014). The Routledge handbook of language and health communication. London: Routledge.

Harrison, Sandra, \& Barlow, Julie (2009). Politeness strategies and advice-giving in an online arthiritis workshop. Journal of Politeness Research, 5(1), 93-111.

Hawkins, Anne Hunsaker (1993). Reconstructing illness: Studies in pathography. West Lafayette, IN: Purdue University Press.

Hawkins, Anne Hunsaker, \& McEntyre Chandler, Marilyn (Eds.) (2000). Teaching literature and medicine. New York, NY: Modern Language Association.

Hawthorn, Jeremy (2000). A glossary of contemporary literary theory. London: Arnold.

Hunter, Kathryn Montgomery (1991). Doctors'stories: The narrative structure of medical knowledge. Princeton, NJ: Princeton University Press.

Hurwitz, Brian (2006). Form and representation in clinical case reports. Literature and Medicine, 25(2), 216-240. DOI: 10.1353/Im.2007.0006

Hurwitz, Brian (2010). What is narrative medicine? Why does it matter? Lecture presented at the University of Basel.

Hurwitz, Brian, Greenhalgh, Tisha, \& Skultans, Vieda (Eds.) (2004). Narrative research in health and illness. Malden, MA: Blackwell. DOI: 10.1002/9780470755167

Hydén, Lars-Christer, \& Brockmeier, Jens (Eds.) (2008). Health, illness and culture. Broken narratives. London: Routledge.

Johnstone, Barbara (1990). Stories, community, and place: Narratives from Middle America. Bloomington, IN: Indiana University Press.

Jones, Anne Hudson (2013). Why teach literature and medicine? Answers from three decades. Journal of Medical Humanities, 34(4), 415- 428. DOI: 10.1007/sI0912-013-9241-9

Jurecic, Ann (2012). Illness as narrative. Pittsburgh, PA: University of Pittsburgh Press.

Klapproth, Danièle (2004). Narrative as social practice. Anglo-Western and Australian aboriginal oral traditions. Berlin: Mouton de Gruyter. DOI: $10.1515 / 9783110197426$

Kleinman, Arthur (1988). The illness narratives: Suffering, healing and the human condition. New York, NY: Basic Books.

Kouper, Inna (2010). The pragmatics of peer advice in a LiveJournal community. Language@Internet, 7, article 1. Retrieved from (http://www.languageatinternet.org/articles/2010/2464)

Labov, William (1972). Language in the inner city. Studies in the black English vernacular. Philadelphia, PA: University of Pennsylvania Press.

Labov, William (1997). Some further steps in narrative analysis. Journal of Narrative and Life History, 7, 395-415.

Labov, William (2013). The language of life and death. The transformation of experience in oral narrative. Cambridge: Cambridge University Press. DOI: 10.1017/CBO9781139519632

Labov, William, \& Fanshel, David (1977). Therapeutic discourse. New York, NY: Academic Press. 
Labov, William, \&Waletzky, Joshua (1967). Narrative analysis: oral versions of personal experience. In J. Helm (Ed.), Essays on verbal and visual Arts (pp. 12-44). Seattle, WA: University of Washington.

Locher, Miriam A. (2006). Advice online. Advice-giving in an American internet health column.

Amsterdam: John Benjamins. DOI: 10.1075/pbns.149

Locher, Miriam A., \& Koenig, Regula (2014). "All I could do was hand her another tissue" Handling emotions as a challenge in reflective writing texts by medical students. In $A$. Langlotz \& A. Soltysik Monnet (Eds.), Emotion, affect, sentiment: The language and aesthetics of feeling (in press). Tübingen: Narr.

Lucius-Hoene, Gabriele, \& Deppermann, Arnulf (2004). Rekonstruktion narrativer Identität: Ein Arbeitsbuch zur Analyse narrativer Interviews. Wiesbaden: VS Verlag für Sozialwissenchaften. Mann, Thomas (1924). Der Zauberberg [The magic mountain]. Berlin: Fischer.

Martinez, Matias, \& Scheffel, Michele (2002). Einführung in die Erzähltheorie. München: Verlag $\mathrm{CH}$. Beck.

Mattingly, Cheryl, \& Garro, Linda C. (Eds.) (2000). Narrative and the cultural construction of illness and healing. Berkeley/Los Angeles, CA: University of California Press.

Oyebode, Femi (Ed.) (2009). Mindreadings: Literature and psychiatry. London: Royal College of Psychiatrists.

Sarangi, Srikant (in press, 2015). Owning responsible actions/selves: Role-relational trajectories in counseling for childhood genetic testing. In J.-O. Ostman \& A. Salin (Eds.), Discourse and responsibility in professional settings. London: Equinox.

Schegloff, Emanuel (1997). 'Narrative analysis' thirty years later. Journal of Narrative and Life History, 7, 97-106.

Schiffrin, Deborah (2000). Mother/daughter discourse in a holocaust oral history: 'Because then you admit that you're guilty: Narrative Inquiry, 10(1), 1-44. DOI: 10.1075/ni.10.1.0lsch

Sedgwick, Eve (2003). Touching feeling: Affect, pedagogy, performativity. Durham, NC: Duke University.

Smithson, Janet, Sharkey, Siobhan, Hewis, Elaine, Jones, Ray, Emmens, Tobit, Ford, Tamsin, \& Owens, Christabel (2011). Problem presentation and responses on an online forum for young people who self-harm. Discourse Studies, 13(4), 487-501. DOI: 10.1177/1461445611403356

Squier, Susan M. (1994). Babies in bottles: Twentieth century visions of reproductive technology. New Brunswick, NJ: Rutgers University Press.

Squier, Susan M. (2008). Literature and medicine, future tense: Making it graphic. Literature and Medicine, 27(2), 124-152. DOI: 10.1353/Im.0.0031

Whitlock, Gillian (2006). Autographics: The seeing 'I' of the comics. Modern Fiction Studies, 52(4), 965-979. DOI: 10.1353/mfs.2007.0013 